\title{
Carlos Salas da forma
}

\author{
Carlos Salas Shapes
}

\author{
Juan Gustavo Cobo Borda (Colombia) \\ Escritor \\ coborda@gmail.com
}

\section{Resumen}

En este escrito se describe la obra del maestro Carlos Salas Silva como un constante ejercicio exploratorio sobre la forma, que evoca multiples atmósferas plásticas. Metaforas sobre el encierro, mapas, marcas y confrontaciones con el pasado, son parte del territorio visual sobre el que transita el artista.

Palabras clave: pintura abstracta, Carlos Salas, artistas colombianos, pintura, Kairos.

\section{Abstract}

This article describes the work of the Master Carlos Salas Silva as an exploratory exercise about shape recalling multiple plastic art atmospheres. Metaphors about seclusion, maps, marks, and confrontations of the past are part of the visual territory presented by the artist.

Keywords: abstract painting, Carlos Salas, Colombian artists, painting, Kairós. 
Una primera mirada a la obra de Carlos Salas nos ofrece cuadros que corresponden a un patron que llamaría geométrico o clásico y otros que se internan en una exploración informal y libérrima. Del tablero de ajedrez a la pulsión errante. El primer grupo se estructura a partir de rectángulos de color que como marco, reja o ventana, nos abren otro espacio, un trasfondo sugerente, salpicado de insinuaciones plásticas. Algo que en alguna forma la mirada debe armar $y$ recomponer. Porque si algo distingue a Salas es su tarea de configurador.

La otra serie señalada se presenta como un ovillo en expansión, mas caótica y abigarrada, de atmósferas sombrías, de la cual podrían deducirse metáforas de encierro o laberinto, de nudos superpuestos, $y$ de una claustrofobia visual, que al rasgarse brinda atisbos de luz, como en "cruce de tiempos" donde conjugan las dos maneras. Un mapa, una topografía, y a la vez unas marcas, y en cierto modo uno tipografía blanca, que eslabona el contrapunto de su pentagrama de luz y sombra. De concentración y despliegue. De inmersión en la matriz subconsciente y también de exploración en los espacios siderales.

Como sucedió en su gran retrospectiva en el Museo de Arte Moderno de Bogotá, con el título de Kairos (1999-2014) el centro productor de su tarea es el taller del artista, recreado en esa muestra, con sus fetiches y referentes, sea un cuadro colonial de

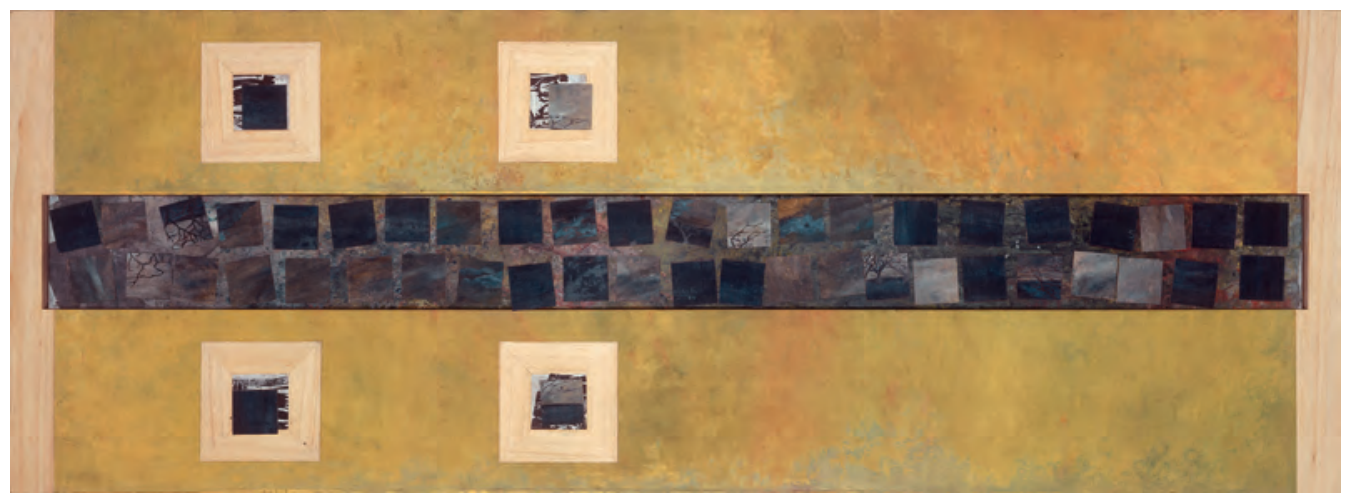

1963-Parte 2. Mixta sobre tela, madera y metal. $76 \times 210 \mathrm{~cm} 1974-1992$ 


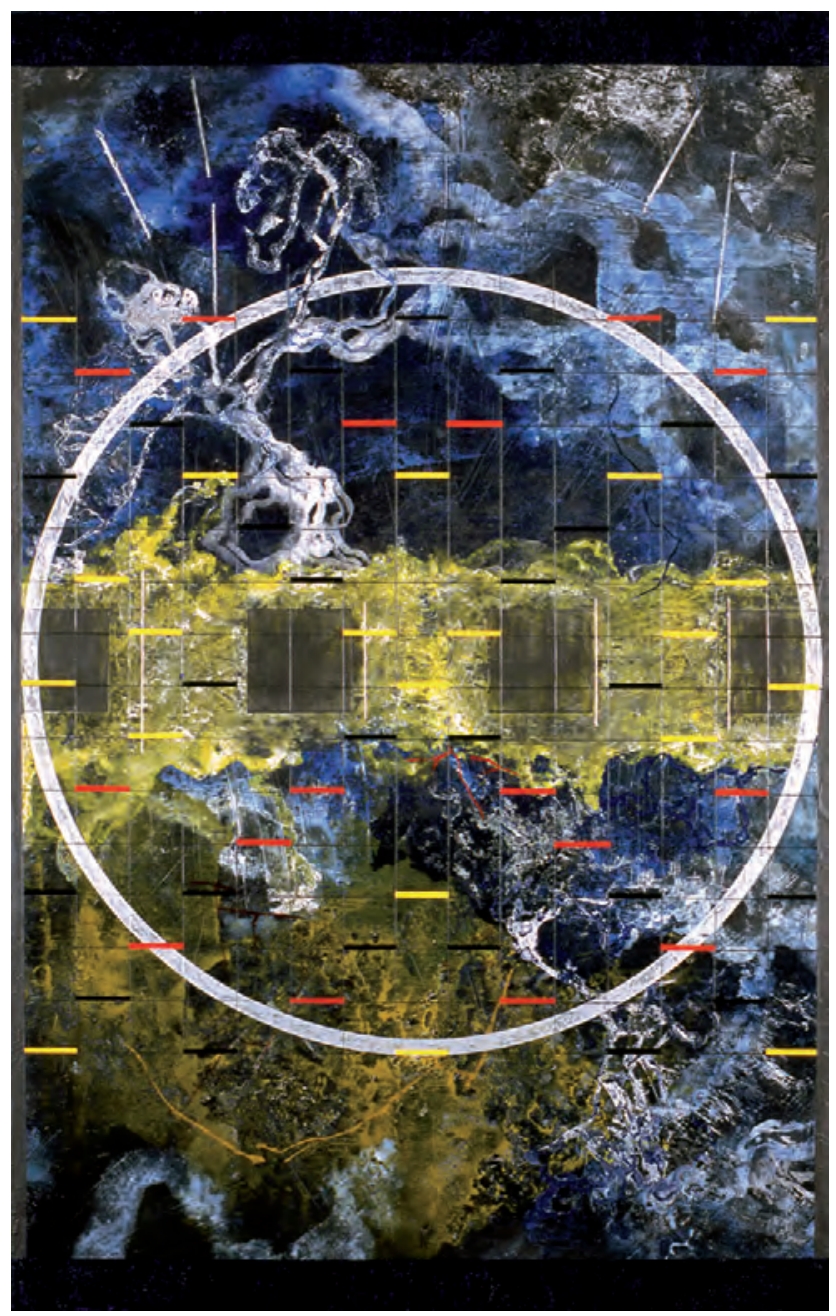

Retorno. Mixta sobre tela. 195x121 cm 2006

Gregorio Vasquez o una escultura ya legendaria, como la "Bachue" de Romulo Rozo, intervenida por Salas.

Pero ese diálogo y confrontación con el pasado es también una recapitulación crítica de lo que el también ha hecho. Por ejemplo, en un momento dado, corto y deshizo sus viejos óleos para componer con ellos nuevas obras, en solitario o con la colaboración de colegas.

Además, sus estadáas en Francia, como estudiante o investigador, señalan otras de sus rutas de exploración. Tal el caso de la galería "Mundo" que durante una década (2001-2011) 


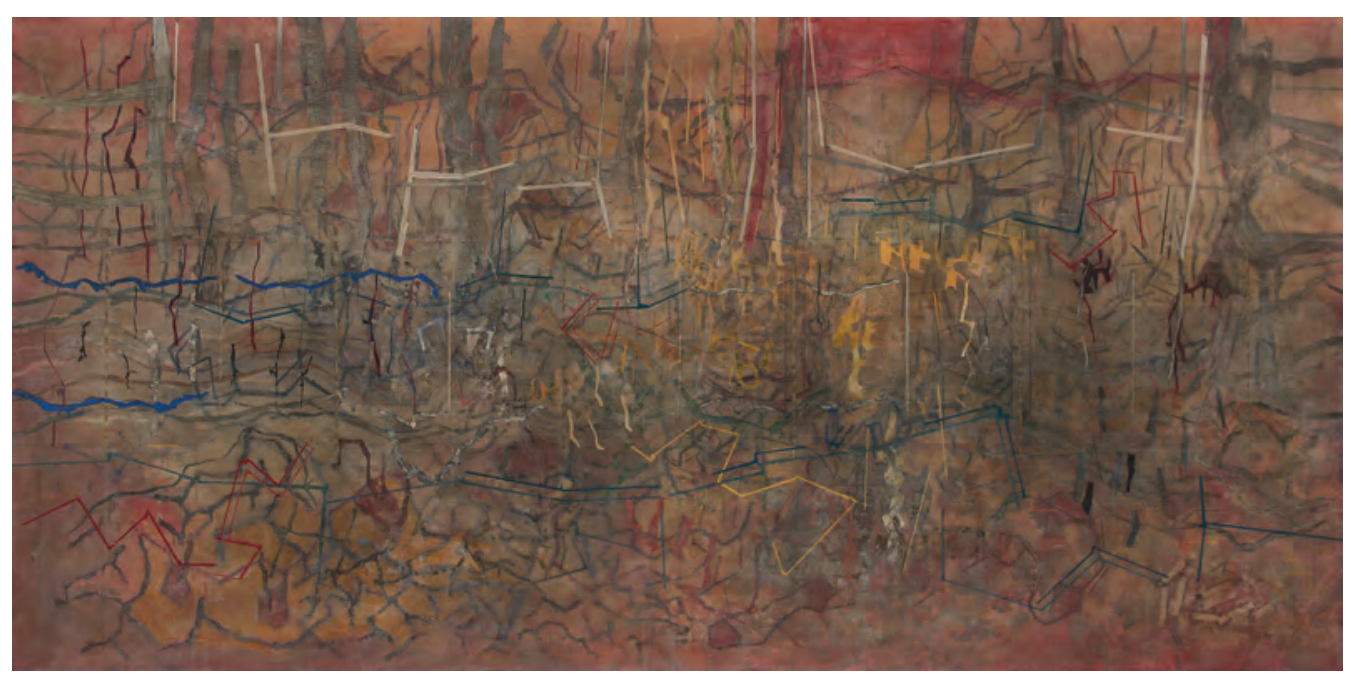

Cuadro 6 de doce cuadros doce historias. Acrílico sobre tela. 183×380cm 2011

fundó y dirigió en las Torres de Salmona y con la cual logró la hazaña de los 40 números del la revista del mismo nombre, "Mundo", donde deben consignarse nombres de artistas estudiados, a todo color, que abarcan de Obregón y Botero, a Rayo, Grau, Eduardo Ramírez, Negret, Ana Mercedes Hoyos, porcriticos y escritores de valía. De arquitectos como Rogelio Salmona y Daniel Bermudez o temas de tan singular relevancia como todos los ganadores del Salon Nacional, quienes tambien quedaron censados. Pero Salas persiste, insiste, como lo comprueba "En el taller" (2014) una obra de 300 $\mathrm{cm}$. de diametro que vibra con una intensidad electrica en esos amarillos
- azules y verdes que se superponen y contrastan en su escritura plastica que parece rota y fragmentada pero que termina por componer el mapamundi astral del universo.

Es interesante señalar que el modus operandi de Salas se da de forma horizontal, sobre una vasta mesa, y no como es habitual en el caballete vertical o en la pared. El artista se inclina sobre si mismo y se asedia asi desde todos los angulos, vivencias y recuerdos, personas y viajes, referencias y olvidos. El microcosmos del detalle examinado queda englobado en el conjunto de la tela y esta a su vez conforma largas secuencias como en "Recorridos desde un lugar de la memoria en 42 pasos" (2000) o 
"Doce cuadros doce historias" (2011) que muestra su voluntad de agotar la propuesta en forma exhaustiva y con múltiples formas de abordaje. Salas sabe que las imagenes son inagotables en su persistencia e irradiación. El pintor aleman Hans Trier (1873-1962) escribio : "Pintar significa danzar en un espacio coherente sobre la superficie susceptible de abarcarse de una ojeada : el ritmo danza en el fluir, en el staccato, en la pausa, en el retorno de los pinceles" (471). Tal como Salas lo logra en esta trayectoria tan consolidada.

\section{Bibliografía}

Toro, J.E. y Gomez, F. (2000) Salas paso apaso. Ediciones El Museo: Bogotá.

Medina, Alvaro. (1999) Salas, pintura activa. Museo de Arte Moderno de Bogotá: Bogotá.

Cuartas, Pablo (2014) Carlos Salas. Kairos. Museo de Arte Moderno de Bogotá: Bogotá.

Trier, Hans (1965) "Como pinto un cuadro”. Revista Eco. Tomo XI/5. (pp. 457-472). 